\title{
PEDAGOŠKI ASPEKTI PRIMENE KONCEPTA ISHODA UČENJA U VISOKOŠKOLSKOJ NASTAVI**
}

$\mathrm{U}$ radu se razmatra problematika definisanja, planiranja i upotrebe ishoda učenja u visokoškolskoj nastavi, kao jednog o ključnih aspekata nastavnog rada. Koncept ishoda učenja posebno je aktuelizovan Bolonjskim procesom i predstavlja značajan alat za planiranje nastavnog rada i kreiranje kurikuluma kao i za prepoznavanje stečenih znanja i veština studenata. Analizirani su relevantni dokumenti u okviru reforme visokog obrazovanja kojima se ističe značaj ishoda učenja za usaglašavanje različitih sistema visokog obrazovanja u okviru Evrope. Akcenat je stavljen na pedagoške implikacije upotrebe ishoda učenja i na njihov značaj za nastavni rad, posebno iz perspektive pristupa usmerenog na studenta. Dat je prikaz konkretnih uputstava i smernica za kreiranje i definisanje ishoda učenja. Prikazana je SOLO taksonomija kao jedna od značajnijih taksonomija za pisanje ishoda učenja u visokom obrazovanju i za procenjivanje usvojenih znanja i veština studenata. Rezultati ukazuju na to da ishodi učenja predstavljaju konstrukt koji omogućava nastavnicima efikasno planiranje i organizovanje nastave, kao i procenjivanje stečenog znanja i kompetencija studenata. Sa druge strane, studentima omogućava mobilnost na druge univerzitete, priznavanje stečenih kvalifikacija, priznavanje prethodnog učenja i dr. Zaključuje se da adekvatna implementacija ishoda učenja u nastavnu praksu, studijske programe i predmete u značajnoj meri utiče na kvalitet obrazovanja.

Ključne reči: ishodi učenja, nastava, visoko obrazovanje, studenti, nastavnici, Bolonjski proces.

Oblast visokog obrazovanja i sve visokoškolske institucije pretrpele su značajne promene još od početka devedesetih godina prošlog veka i, sa tim u vezi, nastojanja svih država ujedinjene Evrope usmerila su se ka tome da se sistem visokog obrazovanja učine konkurentnijim i efikasnijim, da Evropa postane vodeća ekonomija u svetu i društvo zasnovano na znanju (European Council, 2000, para.

\footnotetext{
*biljana.lungulov@ff.uns.ac.rs

** Rad je nastao kao rezultat rada na projektu „Kvalitet obrazovnog sistema Srbije u evropskoj perspektivi“, br. 179010 (2011-2016), čiju realizaciju finansira Ministarstvo prosvete, nauke i tehnološkog razvoja Republike Srbije. U radu su korišćeni delovi rezultata dobijenih u okviru doktorske disertacije pod nazivom "Analiza ishoda učenja kao indikatora kvaliteta visokog obrazovanja" odbranjene na Filozofskom fakultetu, Univerziteta u Novom Sadu.
} 
5). U skladu sa tim, sprovedene reforme realizovane su sa ciljem „evropeizacije visokog obrazovanja“ (de Wit, 2007: 473) koja je podrazumevala intenziviranje mobilnosti studenata i zaposlenih, usaglašavanje stečenih kvalifikacija, kompatibilnost studijskih programa, izgradnju mreža i povezivanje visokoškolskih institucija, transnacionalnu saradnju i sl. Može se reći da su ova nastojanja ostvarena kada je 2010. godine zvanično formiran Evropski prostor visokog obrazovanja.

Radi ostvarenja postavljenih ciljeva predviđenih Bolonjskom deklaracijom, sprovedene su temeljne i zahtevne reforme koje su se odnosile na svaki aspekt visokog obrazovanja. Podrazumevali su promene počevši od organizacije visokoškolskih institucija, preko sistema upravljanja i vođenja, implementacije kontrole kvaliteta, do izmene planova i programa, osavremenjivanja metoda i sredstava u nastavnom radu, povezivanja sa istraživačkim institutima i tržištem rada, sve do drugačijeg pristupa u nastavnom radu koji podrazumeva pristup usmeren na studenta.

Kao rezultat takvih nastojanja, kreirani su posebni alati koji su našli svoju široku primenu u okviru sistema visokog obrazovanja. Drugim rečima, kako bi bilo moguće realizovati postavljene ciljeve, uvedeni su alati kao što su evropski sistem prenosa bodova (ESPB), Dodatak diplomi, ishodi učenja, Ugovor o učenju i dr. Ovim i sličnim alatima omogućeno je usaglašavanje različitih sistema i načina studiranja u Evropi, priznavanje ranijeg učenja, mobilnost studenata, priznavanje stečenih kvalifikacija na evropskom tržištu rada, planiranje i organizacija nastave, vrednovanje stečenih znanja i kompetencija studenata i dr.

U nastavku rada posebno će biti razmatrani ishodi učenja, koji predstavljaju neophodan i nezaobilazan aspekt kreiranja kurikuluma, planiranja i organizovanja nastavnog rada, provere usvojenih znanja i veština studenata, sticanje adekvatnih kvalifikacija, mobilnost studenata i zaposlenih i dr.

\section{ISHODI UČENJA U KONTEKSTU REFORME VISOKOG OBRAZOVANJA}

Uvođenjem koncepta ishoda učenja u proces reforme visokog obrazovanja u Evropi akcentovana je potreba definisanja i prepoznavanja ciljeva određenog studijskog programa, delova programa, kao i pojedinačnih kurseva. Koncept ishoda učenja detaljnije je razmatran na ministarskoj konferenciji u Pragu 2001. godine (Prague communiqué, 2001) i nakon toga je na svakoj od narednih ministarskih konferencija nastavljen proces njegovog definisanja, utemeljenja i implementacije $u$ nacionalnu i transnacionalnu politiku visokog obrazovanja. Na konferenciji u Berlinu 2003. godine, zaključeno je da ministri pružaju podršku zemljama 
članicama da uspostave okvir uporedivih i kompatibilnih kvalifikacija za nacionalni obrazovni sistem, koji bi trebalo da definiše stečene kvalifikacije pomoću elemenata kao što su radno opterećenje, nivo studija, ishodi učenja, kompetencije i stečeni profil (Berlin communiqué, 2003).

Na ministarskim konferencijama koje su kasnije održane i u nastojanjima u okviru Bolonjskog procesa, upotreba ishoda učenja dodatno je proširena i razrađena. Tako je u Bergenu zaključeno da se usvaja okvir kvalifikacija u okviru Evropskog prostora visokog obrazovanja koji podrazumeva kvalifikacije za tri ciklusa studija i da opšti deskriptori za svaki od nivoa studija treba da budu zasnovani na ishodima učenja i kompetencijama (Bergen communiqué, 2005). Na ministarskoj konferenciji u Londonu 2007. godine zaključeno je da visokoškolske institucije treba da omoguće lakši prelazak sa jednog na drugi nivo studija na taj način što će nivoi biti definisani preko ESPB bodova i ishoda učenja (London communiqué, 2007).

„Dakle, u dvadeset i prvom veku, ishodi učenja najbolje su sagledani kao ključni blok u izgradnji Bolonjskih reformi. To je iz razloga što predstavljaju praktičan alat i metodološki pristup koji je usvojen da bi se unapredila konkurentnost, transparentnost, prepoznavanje i mobilnost evropskog obrazovanja“ (Adam, 2006: $3)$.

Takođe, značajni napori u okviru izmena i unapređenja sistema visokog obrazovanja usmereni su i na realizaciju i povećanje zapošljivosti studenata, njihovu konkurentnost na tržištu rada, razvoj potrebnih kompetencija za život i rad u 21. veku, što u fokus stavlja formulisanje adekvatnih ishoda učenja i kreiranje kurikuluma. U skladu sa tim, značajne konstatacije su donete na konferenciji u Bukureštu, gde se ističe da studenti treba da kombinuju transverzalne, multidisciplinarne i inovativne veštine i kompetencije sa aktuelnim područno specifičnim znanjima kako bi bili u mogućnosti da doprinose širokim društvenim potrebama i tržištu rada. Takva nastojanja mogu se ostvariti razvojem studijskih programa koji podstiču i razvijaju inovativni, preduzetnički i istraživački potencijal studenata (Bucharest Communiqué, 2012).

Značajno je napomenuti da shodno svim reformama ishodi učenja imaju svoju primenu na tri različita nivoa: lokalni nivo pojedinačnih visokoškolskih institucija (ishodi koji se odnose na predmete/module, programe studija i kvalifikacije), nacionalni nivo (okvir kvalifikacija i načine osiguranja kvaliteta) i internacionalni nivo (za šire svrhe prepoznavanja i transparentnosti) (Adam, 2006). $\mathrm{Na}$ taj način se tokom protekle decenije koncept ishoda učenja dodatno unapređivao 
i od početne ideje razvio u nezaobilazni element svakog sistema visokog obrazovanja i visokoškolskih institucija u okviru Evrope.

\section{PEDAGOŠKI ASPEKTI UPOTREBE ISHODA UČENJA U VISOKOŠKOLSKOJ NASTAVI}

Međunarodni trendovi $\mathrm{u}$ obrazovanju ukazuju na sve evidentnije premeštanje fokusa interesovanja od pristupa u čijem je središtu profesor ka pristupu obrazovanju koje je više orijentisano na ishod (Kennedy, 2007). Taj trend dobio je nov zamah Bolonjskim procesom koji akcenat stavlja na učenje orijentisano na studenta i na potrebu za većom preciznošću i jasnoćom prilikom osmišljavanja nastavnih programa. Adekvatno planiranim ishodima učenja, fokus obrazovnog procesa pomera se sa nastavnika na studenta čime se pruža mogućnost da i studenti učestvuju u procesu kreiranja i definisanja ishoda učenja (From Berlin to Bergen, 2005).

Diskusija o ovim temama postala je deo mnogo šireg procesa koji se zaista može nazvati promenom paradigme u obrazovanju i ona čak nije ograničena samo na visoko obrazovanje. Ovakva promena može biti posmatrana i kao deo širenja koncepta doživotnog učenja i obrazovanja, refleksija promene u studentskoj populaciji, novog načina sprovođenja i organizovanja studijskog programa koja uključuje prelazak sa pristupa usmerenog na nastavnika na pristup usmerenog na studenta, od formalnih definicija (dužina programa i sl.) do definicije kompetencija (Tauch, 2004). Dakle, novi izazov za sve koji učestvuju u razvoju kurikuluma u visokom obrazovanju predstavlja upotreba ishoda učenja tako da se proces učenja sagleda iz ugla studenata, a ne iz ugla potreba nastavnog procesa, te da se na taj način unapredi kvalitet učenja za studente (Allan, 1996). U tom smislu, značajno je navesti ključne karakteristike pristupa usmerenog na studenta prilikom planiranja ishoda učenja i nastavnog rada:

- razvoj jasno definisanih ishoda učenja koji bi trebalo da budu ostvareni pre kraja programa;

- dizajniranje kurikuluma, strategija učenja i uslova za učenje tako da se obezbedi ostvarenje ishoda učenja i

- adekvatne procene koje odgovaraju postavljenim ishodima učenja, kao i procenu svakog studenta da bi se proverilo da li je ostvario postavljene ishode (Harden, 2002: 117). 
Brojni autori u svojim radovima daju pregled definicija ishoda učenja (Allan, 1996; Moon, 2002; Adam, 2006; Kennedy, 2007; Hussey \& Smith, 2003; 2008; James \& Brown, 2005; Kennedy, Hyland \& Ryan, 2012) pri čemu se slažu da još uvek ne postoji njihovo jednoznačno i jasno određenje u visokom obrazovanju, ali da su, ipak, svi navodi u literaturi koncipirani oko nekoliko ključnih elemenata:

- ishodi učenja podrazumevaju očekivane rezultate procesa učenja;

- u fokus stavljaju studenta i odnose se na ono što bi student trebalo da zna i da može da uradi nakon procesa učenja;

- podrazumevaju sticanje znanja, veština i vrednosti;

- obuhvataju različite oblasti koje se odnose na područno specifične, lične i opšte aspekte razvoja;

- fokus je na studentu i na tome šta je on postigao tokom učenja a ne na nastavniku ili nastavnom sadržaju i

- koncipiraju se na nivou pojedinačnih nastavnih jedinica, delova predmeta ili celokupnih predmeta, modula, kao i na nivou studijskih programa.

Prihvaćeno je određenje kojom se ishodi učenja definišu kao „očekivani ili postignuti rezultati programa ili ostvarivanje ciljeva ustanova, što pokazuje širok raspon indikatora (poput znanja studenata, kognitivnih sposobnosti i stavova). Ishodi su rezultati programa poučavanja, planirani u okvirima razvoja osobe koja uči“ (Vlăscenau, Grünberg \& Pârlea, 2007: 63). Ishodi učenja studenata definišu se kao „tvrdnje o tome šta se očekuje da student zna, razume i/ili bude u stanju da pokaže nakon završetka procesa učenja, kao i o specifičnim intelektualnim sposobnostima i praktičnim veštinama koje je usvojio i pokazao, uspešnim savladavanjem dela predmeta, celokupnog predmeta ili programa“ (Vlăscenau, Grünberg \& Pârlea, 2007: 64).

U literaturi se navode podele ishoda učenja na osnovu različitih kriterijuma (James \& Brown 2005; Hussey \& Smith, 2003; 2008), međutim značajno je naglasiti da se oni, takođe, mogu deliti i prema svrsi, odnosno prema tome na koju nastavnu aktivnost ili obrazovnu jedinicu se odnose. U skladu sa tim, Hasi i Smit definišu tri grupe ishoda učenja: (1) ishodi koji se odnose na pojedinačnu nastavnu aktivnost, kao što je seminar, čas ili predavanje; (2) ishodi koji se kreiraju na nivou modula, kratkog kursa ili pojedinačnog predmeta i (3) ishodi koji se odnose na celokupan studijski program koji vodi do sticanja određene kvalifikacije (Hussey \& Smith, 2008). 
Prilikom kreiranja ishoda učenja studijskog programa, značajno je naglasiti da u okviru Evropskog prostora visokog obrazovanja preovlađuju stavovi da definisanje ishoda učenja treba da prethodi kreiranju kurikuluma. $\mathrm{Na}$ taj način se postiže da se nacionalni obrazovni sistemi i studijski programi usklade sa najnovijim naučnim dostignućima, aktuelnim društvenim potrebama i obezbeđuje se kompatibilnost sa studijskim programima u okviru Evropskog prostora visokog obrazovanja. Kreiranje studijskog programa i njemu odgovarajućih ishoda učenja konstantan je proces koji nije statičan niti završen, stoga važno razumeti da je „izrada studijskog programa po svojoj prirodi evolutivni proces. Svaka sledeća iteracija dopunjuje i unapređuje rezultate prethodne iteracije, uz otklanjanje nekonzistentnosti i drugih anomalija“ (Kermek, 2008: 31).

Kada su u pitanju ishodi učenja za pojedinačne predmete ili nastavne jedinice, oni se odnose na relativno specifične i dugotrajne promene kod studenata koji dostignu postavljene ishode, što se može ispoljiti i u ličnom i profesionalnom aspektu razvoja (Hussey \& Smith, 2008). Dakle, u okviru konkretne nastavne jedinice, predavanja ili seminara, nastavnik bi trebalo da isplanira ishode koje je važno ostvariti tokom časa. Zato je veoma značajna nastavnikova priprema za nastavu, jer odlučuje o tome šta će studenti tokom časa saznati. Poželjno je da nastavnik napravi scenario za čas i u njemu definiše očekivane ishode učenja, kao i nastavne metode, sredstva i oblike rada koja će mu omogućiti da se postavljeni ishodi učenja ostvare.

\section{ZNAČAJ PLANIRANJA NASTAVNOG RADA I DEFINISANJA ISHODA UČENJA}

Tokom proteklih godina realizovane su brojne aktivnosti u pogledu implementacije i utemeljenja koncepta ishoda učenja u visokoškolsku obrazovnu politiku. Zaključeno je da prilikom definisanja i pisanja ishoda učenja studijskog programa važe ista ili slična pravila kao pri definisanju ishoda pojedinačnog predmeta. Razlika je u tome što ishodi koji se definišu za studijski program predstavljaju opštije i kompleksnije tvrdnje i odnose se na znanja, veštine i vrednosti koje će studenti steći nakon završetka studijskog programa. Značajno je ukazati na to da ishodi učenja studijskog programa ne predstavljaju samo zbir ili skup definisanih ishoda za pojedinačne predmete. Oni se određuju kao sinteza i pregled ključnih znanja i kompetencija koje predstavljaju očekivani rezultat svih aktivnosti koje se realizuju u okviru određenog studijskog programa.

Jedan od mogućih načina artikulacije planiranih ishoda učenja jeste $A B C D$ model koji predstavlja jedinstveni pristup u pisanju ciljeva programa. Primena ovog 
modela obezbeđuje razvoj i pisanje ishoda učenja dovoljno specifičnih i određenih da budu proverljivi (Carr \& Hardin, 2010). U ovakvom pristupu svako slovo označava jedan aspekt planiranja programa.

- $\mathrm{A}=$ Audience (auditorijum/ciljna grupa/publika) - odnosi se na pojedince $\mathrm{i}$ grupu ljudi koji odgovaraju na određeni tretman i sprovode određene akcije koje se kasnije procenjuju. U kontekstu visokog obrazovanja, ciljnu grupu predstavljaju studenti, stoga bi iskaz o ishodu učenja trebalo početi sintagmom „Studenti će moći da...“.

- $\quad \mathrm{B}=$ Behavior (ponašanje) - podrazumeva akciju koju će prezentovati ili izvesti ciljna grupa. Akcije se definišu rečima kao što su: izvedu, identifikuju, opišu, implementiraju, sprovedu i sl. Podrazumevana akcija definiše se glagolom u rečenici „Studenti će moći da identifikuju...“.

- $\mathrm{C}=$ Condition (uslovi) - predstavlja okolnosti i uslove pod kojima će se određeno ponašanje ispoljiti ili detaljniji opis akcije i ponašanja. U kontekstu visokog obrazovanja podrazumeva vremenski okvir ili okruženje u kojima se učenje odvija i može se odrediti rečima „Studenti će moći da identifikuju... do kraja prvog semestra...".

- $\mathrm{D}=$ Degree (nivo, stepen) - predstavlja merljivi element ishoda učenja. Opisuje koliko dobro određena akcija (ponašanje) treba da bude savladana i dostignuta ili koji nivo određene kompetencije će osoba imati kada se ostvare ishodi učenja. Može biti kvantitativno određen (npr., 85\% tačnih odgovora, maksimalno tri greške i sl.) i kvalitativno (bez pomoći nastavnika, uspešno, u skladu sa uputstvima i sl.) (Carr \& Hardin, 2010: 141-142).

Prilikom definisanja ishoda učenja pojedinačnog nastavnog predmeta poželjno je da se pretpostavi minimum standarda koje studenti treba da ostvare i iz tog razloga je u pretpostavljene ishode nužno staviti ključne elemente i sadržaje predmeta. Takođe, broj ishoda koji se definišu nije određen, niti unapred propisan i zavisi od različitih faktora. Oni se tiču konkretnog nastavnog predmeta i odnose se na: obim sadržaja i literature, položaj predmeta u studijskom programu, trajanje predmeta i aktivnosti studenata i sl., ali se većina autora slaže da je optimalan broj od pet do devet definisanih ishoda u okviru jednog predmeta. Pojedini autori navode da se ishodi učenja definišu terminima student će... (moći da uradi).... Međutim, ističu i da je adekvatnije koristiti izraz očekuje se da će student moći da... jer se smatra da nastavnik nema stvarnu kontrolu nad studentskim učenjem (Moon, 2002). 
„Može se desiti da student jednostavno ne dođe na predavanje. Suština je, dakle, u tome da niko ne može da prisili i natera studenta da uči ili nauči, nego se jedino možemo nadati da će se učenje desiti. Samo postojanje i definisanje konkretnih ishoda učenja ne znači po sebi da će student ustati iz kreveta i doći na predavanje. Stoga, ishodi učenja predstavljaju materijal koji naglašava razliku između aktivnosti koje se odnose na poučavanje i učenje - a učenje predstavlja proces koji jedino student može da kontroliše“"(Moon, 2002: 56).

Većina univerziteta i veliki broj autora kreirali su posebna uputstva i sugestije na koji način pisati i definisati ishode učenja (Moon, 2002; Kennedy, 2007; Wilde \& Hardaker, 2007; Erjavec, 2008; Biggs \& Tang, 2011). Na osnovu analize dostupnih publikacija u nastavku je izneta sinteza i pregled najznačajnijih aspekata koji sugerišu načine pisanja ishoda učenja i predstavljaju svojevrsnu pomoć nastavnicima prilikom planiranja i organizovanja sopstvenog rada. Prilikom koncipiranja ishoda učenja pojedinog nastavnog predmeta važno je odgovoriti sledećim zahtevima:

- definisati šta bi student trebalo da zna/može da uradi;

- ishod učenja je nabolje formulisati kao nastavak rečenice: Nakon učenja student će moći da...;

- koristiti aktivne glagole koji označavaju radnju (primeniti, pokazati, evaluirati), a izbegavati glagole kao što su znati, prepoznati, definisati i sl.;

- uskladiti ishode učenja predmeta sa definisanim ishodima na nivou studijskog programa;

- ishode treba definisati jasno i jednostavno, kako bi bili razumljivi svim zainteresovanim stranama;

- jasno definisati kriterijume ostvarenja ishoda koji bi trebalo da podrazumevaju minimum potrebnog postignuća za uspešno završavanje kursa;

- definisani ishodi treba da reflektuju kriterijume provere ostvarenosti;

- potrebno je adekvatno odrediti akademske kredite za konkretne ishode učenja (Wilde \& Hardaker, 2007: 13);

- koristiti adekvatnu taksonomiju kao pomoć prilikom definisanja ishoda učenja;

- poštovati pravilo: jedan glagol - jedan ishod učenja;

- identifikovati od četiri do osam ishoda za jedan predmet (Erjavec, 2008: 66);

- opisati suštinu učenja u okviru kursa; 
- navoditi minimalni prihvatljivi nivo koji omogućuje studentu da položi ispit;

- definisati manji broj važnih ishoda učenja, umesto većeg broja isuviše detaljnih ili opštih i površnih ishoda (Kennedy, 2007: 52).

Postoji i čitav niz sličnih uputstava o tome na koji način bi trebalo definisati i napisati ishode učenja u okviru pojedinačnih predmeta. Autori se slažu da svi moraju biti jasno i precizno definisani i odražavati minimum standarda koje je potrebno da student zadovolji kako bi položio određeni ispit. Značajno je navesti bitne korake koje treba slediti u definisanju ishoda učenja predmeta: (1) razmotriti ciljeve predmeta, (2) napisati ishode učenja, (3) osmisliti zadatke za proveru ishoda učenja, (4) definisati granične kriterijume ocenjivanja, (5) razviti strategiju poučavanja, (6) prosuditi postizanje ishoda učenja (Erjavec, 2008: 71).

Druga grupa autora navodi da se proces određivanja i definisanja ishoda učenja pojedinačnog predmeta može podeliti u pet faza: (1) formulisati ideal ili cilj, (2) napraviti listu prideva koji opisuju idealne karakteristike studenta konkretne oblasti (veštine, znanja, lični kvaliteti), (3) definisati kompetencije ili klastere ključnih aktivnosti u okviru polja proučavanja, (4) napisati ishode učenja, (5) napisati grupe izjava koje opisuju šta je potrebno da student zna ili uradi da bi demonstrirao ostvarene ishode (Wilde \& Hardaker, 2007: 11-12).

Međutim, ono što je takođe posebno značajno jeste da u proces kreiranja $\mathrm{i}$ pisanja ishoda učenja treba uključiti studente. Iako ishode najčešće formulišu nastavnici, sugeriše se da bi ih trebalo dizajnirati i iz ugla studenata, jer je to značajna karakteristika koja ih razlikuje od konvencionalnih obrazovnih ciljeva koji se definišu samo iz perspektive nastavnika. Ishode učenja treba da dostignu studenti (ovo implicira reč učenje u sintagmi ishodi učenja), a uloga nastavnika je da facilitira taj proces (Castillo, Caruana \& Wainwright, 2011). Dakle, iako postoji niz različitih shvatanja o procesu kreiranja i definisanja ishoda učenja, elementima koje treba da sadrži, broju ishoda i sl., većina autora se slaže u vezi sa načinom njihovog definisanja i određenja na nivou predmeta. Na osnovu zajedničkih stavova, konkretna uputstva i pravila mogu se smatrati opštim jer se mogu primeniti na sve obrazovnonaučne oblasti.

Kao svojevrsna pomoć prilikom pisanja i formulisanja ciljeva i zadataka nastavnog procesa i ishoda učenja, kao i planiranja nastavnog rada, sugeriše se upotreba adekvatne taksonomije ciljeva i zadataka nastave. U naukama o obrazovanju taksonomija obrazovnih ciljeva predstavlja „okvir za klasifikaciju tvrdnji i izjava o tome šta se očekuje ili planira da studenti nauče kao rezultat nastave“ (Krathwohl, 
2002: 212). U literaturi su poznate brojne taksonomije (npr. Blumova taksonomija (Bloom at. al 1956; Krathwohl, 2002) Koksova taksonomija (Cox, 2003), Karterova taksonomija (Carter, 1985, prema: Otter, 1992), Finkova taksonomija (Fink, 2003; 2009), SOLO taksonomija (Biggs \& Collis, 1982), od kojih svaka na određeni način operacionalizuje ciljeve i zadatke nastave i obrazovanja i kategoriše nivoe znanja i razumevanja nastavnih sadržaja. Međutim, nije svaka taksonomija pogodna sa svaki nastavni sadržaj i predmet. Stoga je važno odrediti onu taksonomiju koja na adekvatan način omogućuje postavljanje i definisanje obrazovnih ciljeva i odgovara konkretnom nastavnom sadržaju.

U nastavku će biti prikazana SOLO (Structure of Observed Learning Outcomes) taksonomija Bigsa i Kolisa koja je posebno značajna i primenljiva u kontekstu visokog obrazovanja. Oni su u knjizi Evaluacija kvaliteta učenja: SOLO taksonomija definisali poseban pristup u određivanju nivoa kompetencija koji ne služi samo pisanju ishoda učenja nego i kao adekvatan kriterijum procene studentskih odgovora i nivoa znanja (Biggs \& Collis, 1982). Bigsova SOLO taksonomija predstavlja utemeljenu hijerarhiju koja se sastoji od pet nivoa kompetencija i sadrži rangove od nekompetentnosti do ekspertize (O’Neill \& Murphy, 2010). Nivoi opisuju koliko dobro su studenti razumeli određeni sadržaj i primenljivi su na svaku oblast proučavanja. Bigs navodi pet nivoa znanja i razumevanja sadržaja, odnosno odgovora koje studenti daju, koji su hijerarhijski određeni:

- Prestrukturalni nivo - na kojem studenti prilikom odgovaranja koriste tautologiju da bi prikrili nedostatak znanja i razumevanja. Odgovori mogu biti sofisticirani, ali akademski ne daju dovoljno dokaza o učenju.

- Unistrukturalni nivo - označava realizaciju samo jednog dela postavljenog zadatka i definiše pristup učenju iz najadekvatnijeg aspekta, zapostavljajući druge aspekte koji takođe mogu biti relevantni za razumevanje.

- Multistrukturalni nivo - podrazumeva usmerenost na više aspekata zadatka, ali nema dovoljne strukturalne povezanosti među njima. Studenti raspolažu velikim brojem činjenica koje nisu povezane u celinu. Kod ovakvog odgovora „studenti vide drveće, ali ne i šumu“.

- Relacioni nivo - predstavlja nivo na kojem studenti poznaju veliki broj činjenica, ali daju i objašnjenja koja povezuju detalje u celinu. Student može da navede primere i struktura se može koristiti da generiše praktične korake. Desila se kvalitativna promena u učenju i razumevanju i „drveće 
je postalo šuma“. Ovo je prvi nivo na kojem razumevanje u akademskom smislu može adekvatno da se upotrebi.

- Nivo proširene apstrakcije - nivo znanja i razumevanja na kojem student prevazilazi ono što mu je bilo dato, dok relacioni odgovor ostaje $u$ okvirima onoga što je dato. Koherentna celina je konceptualizovana na višem nivou apstraktnosti i može se primeniti na nove i šire oblasti. Problem je jedino što trenutni odgovor, koji je na nivou proširene apstrakcije, kasnije postaje početni koncept na relacionom nivou (Biggs \& Tang, 2011: 88-90).

Ona se koristi ne samo kao pomoć prilikom pisanja ishoda učenja, nego i da bi se adekvatnije kategorizovali odgovori studenata i često se koristi kao kriterijum procenjivanja znanja studenata. Takođe, u okviru osnovnih smernica za definisanje i pisanje ishoda učenja posebno je značajan aspekt procene ostvarenosti i analize uspeha studenata. Deo literature koja se bavi problematikom ishoda učenja u visokom obrazovanju poseban akcenat stavlja na značaj adekvatnog procenjivanja i analize ostvarenosti ishoda i ciljeva obrazovanja.

Dakle, kvalitet visokog obrazovanja je u značajnoj meri određen kvalitetom studijskog programa (kurikuluma) i posebno kvalitetom ostvarenosti ishoda učenja ili razvijenim kompetencijama. Zato ih treba definisati pažljivo i odgovorno, jer se u zavisnosti od stepena njihovog ostvarenja i realizacije, dobija relevantna povratna informacija o pozitivnim aspektima, ali i eventualnim poteškoćama i problemima $\mathrm{u}$ realizaciji obrazovnog procesa.

\section{ZAKLJUČAK}

Tokom protekle decenije pojam ishodi učenja više je dobio na značaju i njegova upotreba proširena je na sve sfere visokog obrazovanja sa ciljem unapređenja kvaliteta obrazovanja. Takođe, termin je sve više počeo da se koristi u naučnoj i stručnoj literaturi, realizuju se istraživanja sa ciljem da se analiziraju i procene ostvareni ishodi, organizuju se obuke nastavnog kadra za njihovu što veću i adekvatniju upotrebu, čime ishodi učenja dobijaju sve značajnije mesto u praksi visokog obrazovanja. Međutim, iako je evidentna ekspanzija i veća zastupljenost ishoda učenja u visokom obrazovanju još uvek se vode diskusije o njihovim krajnjim dometima, prednostima i ograničenjima i stoga ne čudi što ih je određena grupa nastavnika i teoretičara prihvatila kao neophodan alat i sredstvo unapređenja rada, dok ih je druga grupa doživela kao teret i nepotrebnu birokratiju. 
Međutim, zaključci upućuju na to da su u okviru obrazovne politike definisane Bolonjskim procesom i reforme visokog obrazovanja, ishodi učenja i kompetencije nakon decenije promena u visokom školstvu zauzeli respektabilno mesto u kreiranju kurikuluma, planiranju nastavnog rada i obezbeđenju kvaliteta obrazovanja.

Biljana Lungulov

\section{PEDAGOGICAL ASPECTS OF LEARNING OUTCOMES CONCEPT AND ITS USE IN HIGHER EDUCATION}

\section{Summary}

The paper discusses the concept of learning outcomes as a relatively new term in educational practice. The introductory part outlines the concept of learning outcomes in the context of the Bologna process and the reform of higher education in Europe. This emphasizes the importance of learning outcomes as a specially designed tool for harmonizing different education systems within the European Higher Education Area. Learning outcomes, accordingly, represent an irreplaceable tool in creating curricula, student and teacher mobility, recognition of previous learning, recognition of acquired qualifications, and planning and organizing teaching as the most important aspect of university teachers' work. An overview of theoretical dispositions, definitions and conceptualizations of learning outcomes is given through the analysis of the different opinions in the literature which showed and examined its key determinants. The focus of the paper is on pedagogical implications and the use of learning outcomes in teaching practice, which primarily relates to the importance of their definition and planning. In other words, the specific ways of writing learning outcomes is discussed, and the instructions and theoretical bases for defining and writing learning outcomes are presented in the context of the new educational paradigm and student-centered learning and approach. Detailed explanation of the SOLO taxonomy of educational goals and tasks is given, which proved to be one of the most significant taxonomies when it comes to planning and organizing teaching in higher education. For this reason, this paper can also be understood as a kind of guidance for the use and writing of learning outcomes. Key results and conclusions indicate that learning outcomes are a construct that helps teachers to adequately plan and organize teaching, as well as to assess the acquired knowledge and competencies of students. On the other hand, it also enables student mobility to other universities, recognizes prior learning, etc. Therefore, the use of learning outcomes significantly contributes to the harmonization of the higher education system in Europe and has an important effect concerning the improvement of quality of higher education.

Key words: learning outcomes, teaching process, higher education, students, teachers, Bologna process. 


\section{LITERATURA}

Adam, S. (2006). An introduction to learning outcomes: A consideration of the nature, function and position of learning outcomes in the creation of the European Higher Education Area. Journal of the European Higher Education Area, Chapter B - Introducing Bologna Objectives and Tools, B. 2.3-1, 1-24.

Allan, J. (1996). Learning outcomes in higher education. Studies in Higher Education, 21(1), 93-108.

Bergen communiqué (2005). The European Higher Education Area - Achieving the Goals, Communiqué of the Conference of European Ministers Responsible for Higher Education, Bergen, 19-20 May 2005, preuzeto sa http://www.ehea.info/Uploads/Declarations/Bergen_Communique1.pdf

Berlin Communiqué (2003). "Realising the European Higher Education Area" Communiqué of the Conference of Ministers responsible for Higher Education in Berlin on 19 September 2003, preuzeto sa http://www.ehea.info/Uploads/Declarations/Berlin_Communique1.pdf

Berlin to Bergen (2005). General Report of the Bologna Follow-up Group to the Conference of European Ministers Responsible for Higher Education Bergen, 19-20 May 2005, preuzeto sa http://www.ehea.info/Uploads/Related\%20EU\%20activities/Report-fromBerlintoBergen-May-2005.pdf

Biggs, J., Tang, C. (2011). Teaching for Quality Learning at University - What the Student Does (4th edition). Maidenhead: The Society for Research into Higher Education \& Open University Press.

Biggs, J. B. and Collis, K. (1982) Evaluating the Quality of Learning: the SOLO taxonomy. New York, Academic Press.

Bloom, B.S. (Ed.), Engelhart, M. D., Furst, E. J., Hill, W. H., \& Krathwohl, D. R. (1956). Taxonomy of educational objectives: The classification of educational goals. Handbook 1: Cognitive domain. New York: David McKay.

Bucharest Communiqué (2012). Making the Most of Our Potential: Consolidating the European Higher Education Area, Bucharest Communiqué, preuzeto sa http://www.ehea.info/Uploads/\%281\%29/Bucharest\%20Communique\%202 $012 \% 281 \% 29 . p d f$

Carr, J. W., Hardin, S. (2010). The Key to Effective Assessment: Writing Measurable Student Learning Outcomes. Recreational Sports Journal, 34, 138-144. 
Castillo, J., Caruana, C. J., Wainwright, D. (2011). The changing concept of competence and categorisation of learning outcomes in Europe: Implications for the design of higher education radiography curricula at the European level. Radiography, 17, 230-234.

Cox, W. (2003). A MATH-KIT for engineers. Teaching Mathematics and its applications, 22(4), 193-198.

de Wit, H. (2007). European Integration in Higher Education: The Bologna Process Towards a European Higher Education Area. In: James J. F. Forest and Philip G. Altbach (Eds.), International Handbook of Higher Education. Dordrecht: Springer. 461-482.

Erjavec, Z. (2008). Ishodi učenja predmeta. U: B. Divjak (Ured.), Ishodi učenja u visokom školstvu. Varaždin: TIVA Tiskara, Fakultet organizacije i informatike. 65-72.

European Council (2000). Presidency conclusions, Lisbon European Council, March 23-24, 2000. preuzeto sa http://www.europarl.europa.eu/ summits/lis1_en.htm

Fink, L. D. (2003). Creating significant learning experiences: An integrated approach to designing college courses. San Francisco: Jossey-Bass.

Fink, D.L, (2009) A self directed guide to designing course for significant learning. preuzeto sa: https://www.bu.edu/sph/files/2014/03/www. deefinkandassociates.com_GuidetoCourseDesignAug05.pdf

Harden, R. M. (2002). Developments in outcome-based education. Medical Teacher, 24(2), 117-120.

Hussey, T., Smith, P. (2008). Learning outcomes: a conceptual analysis. Teaching in Higher Education, 13(1), 107-115.

Hussey, T., Smith, P. (2003). The Uses of Learning Outcomes. Teaching in Higher Education, 8(3), 357-368.

Hussey, T., Smith P. (2002). The trouble with learning outcomes. Active Learning in Higher Education, 3(2), 220-233.

James, M., Brown, S. (2005). Grasping the TLRP nettle: preliminary analysis and some enduring issues surrounding the improvement of learning outcomes. The Curriculum Journal, 16(1), 7-30.

Kennedy, D. (2007). Writing and Using Learning Outcomes. Cork: University College Cork.

Kennedy, D., Hyland, Á., Ryan, N. (2012). Writing and Using Learning Outcomes: a Practical Guide. Journal of the European Higher Education Area, Chapter C - Implementing Bologna in your institution C 3.4-1, 1-30. 
Kermek, D. (2008). Ishodi učenja u okviru postojeće zakonske regulative. U: B. Divjak (Ured.), Ishodi učenja u visokom školstvu. Varaždin: TIVA Tiskara, Fakultet organizacije i informatike. 29-32.

Krathwohl, D. (2002). The Revision of Bloom's Taxonomy: An Overview. Theory into Practice, 41(4), 212-218.

London Communiqué (2007). Towards the European Higher Education Area: responding to challenges in a globalised world, preuzeto sa http://www.ehea.info/Uploads/Declarations/London_Communique18May2 007.pdf

Moon, J. (2002). The Module \& Programme Development handbook. London: Kogan Page Limited.

O’Neill, G., Murphy F. (2010). Assessment - Guide to Taxonomies of Learning. Dublin: UCD Teaching and Learning/ Resources, preuzeto sa http://www.ucd.ie/t4cms/ucdtla0034.pdf

Otter, S. (1992). Learning Outcomes in Higher Education. London: Unit for the Development of Adult Continuing Education.

Prague Communiqué (2001). Towards the European Higher Education Area, Communiqué of the meeting of European Ministers in charge of Higher Education in Prague on May 19th 2001, preuzeto sa http://www.ehea.info/Uploads/Declarations/PRAGUE_COMMUNIQUE.pd f

Tauch, C. (2004). Almost Half-time in the Bologna Process - Where Do We Stand?. European Journal of Education, 39(3), 275-288.

Wilde, F., Hardaker, R. (1997). Clarity is power: learning outcomes, learner autonomy and transferable skills. London: Further Education Development Agency (FEDA). 
